\title{
TRADUZINDO A AMAZÔNIA OS NOVOS ARGONAUTAS E SUAS VIAGENS POSSESSÓRIAS, EXPLORATÓRIAS E UTÓPICAS AO GRÃO-PARÁ DEL MARAÑÓN
}

Seu Sting, meu pajé, quem já viu faisão dourado se abraçar com jacaré?

Por isso, meu caro Sting, vá de swing pra lá, não venha botar molho inglês na goma do meu tacacá. (Composição musical "Meu Pajé”, cantada por Lucinha Bastos)

A fundação da Amazônia é um ato alóctone, posto que o nome advém da mitologia greco-latina, referente às mulheres guerreiras que habitavam a ilha de Lemnos, que estava no caminho dos argonautas, heróis gregos em expedição à Cólquida, onde encontrariam e tomariam o velocino de ouro. As amazonas eram tidas como excelentes arqueiras, manuseando com destreza seus instrumentos de guerra e enfrentando atrozmente seus inimigos, abatendo-os com severidade. Portanto, o batismo da região amazônica é um epônimo, em alusão a essas personagens míticas, o que denota, desde a origem histórica deste espaço, uma estreita relação entre culturas, primeiro em viés de aculturação, posteriormente como interculturalidade.

A partir do século XVI, diversos viajantes estrangeiros, desde militares, religiosos e aventureiros até naturalistas, que na Amazônia aportaram e viajaram, têm em conta esta narrativa de fundação, que acreditamos ser, para além de uma explicação de origem, um índice 
de riqueza da região, primeiramente a riqueza aurífera, tão buscada pelos povos da transição do medieval para o moderno, e posteriormente a riqueza natural e de suas populações. Para Gondim,

Os expedicionários reencontraram e sequenciaram o imaginário dos antigos viajantes, cujas histórias sobre fortunas incríveis - lá Preste João, Grão Khan ou áreas contíguas ao Éden, aqui o Eldorado, lugar fabuloso e a cidade de Manoa das lendárias mulheres guerreiras - estão sempre presentes na invenção da Amazônia (1994, p. 79).

Nesses tempos de fundação da Amazônia, frequentemente as imagens construídas pelo estrangeiro, ou mesmo o nacional não egresso de comunidades autóctones, são eivadas de imaginário e concepções alienígenas, que enfocam em grande parte mais o telúrico - geografia, fauna e flora, com potencialidades exploratórias do que o humano, e quando retratam o nativo é com distanciamento cientificista e objetificação acadêmica. Daí o questionamento da epígrafe, em letra do saudoso poeta Ruy Guilherme Paranatinga Barata (1920-1990): "quem já viu faisão dourado se abraçar com jacaré?". Ufanismo à parte, a interação do eurocentrismo "faisonesco" com o nativismo "jacarístico" tem sido mote para tantos estudos científicos e provocações artísticas, já que o limiar entre a aculturação colonizadora e a interculturalidade decolonial, em geral, nos leva a cisões, quando, ao fim, se declara: "não venha botar molho inglês na goma do meu tacacá".

Este número especial de Cadernos de Tradução, intitulado "Tradução de relatos de viagem sobre a Amazônia", procura lançar-se, e lançar-nos, a essa possível e desejada compreensão do Outro, seja este o narrador/a daquele longínquo momento genético das traduções aqui apresentadas, seja os tradutores e suas introduções esclarecedoras, por vezes nem tanto: dadas as limitações temporais entre $o$ ato de escrever sobre a cultura de origem e $o$ ato de traduzir para a cultura de chegada, as quase enigmáticas referências espaço- 
temporais de alguns narradores/as estrangeiros/as levaram os/as tradutores/as a escolhas conforme sua "ética" moderna, como nos revela Torres em um dos estudos aqui presentes. De todo modo, o que nos chega aos olhos e ouvidos leitores é um autêntico "velo de ouro", revelador talvez mais das idiossincrasias dos/as autores/ es viajantes do que da Amazônia. Compreender essa continental e diversa região requer que façamos em um conjunto de visões e ideologias, o que nesta edição da revista somos agraciados.

Dito isso, a proposta deste número de Cadernos de Tradução inaugura uma série de volumes dedicados à temática da Amazônia, e é um desmembramento do projeto "Indicadores antrópicos: fatores socioambientais e patrimoniais na tradução de índices de antropização em povos e comunidades amazônicas" (PROCAD/ CAPES-Amazônia), cooperação acadêmica que congrega a Pósgraduação em Estudos da Tradução da Universidade Federal de Santa Catarina, a Pós-graduação em Estudos Antrópicos na Amazônia da Universidade Federal do Pará (campus Castanhal) e a Pós-graduação em Ciências Humanas, da Universidade do Estado do Amazonas, com vigência em 2019-2023, que baseia sua proposta na produção de índices da presença e transformação humanas, em seus territórios e ambientes, que considere práticas e valores autóctones de povos e comunidades amazônicas na compreensão da sustentabilidade e do bom viver/bem-estar da população, em vista de contatos culturais e possíveis impactos socioambientais. Por isso, a perspectiva intercultural e interdisciplinar desse projeto, que implica na necessidade de enfoque que releve identidades, patrimônios e hegemonias culturais e suas possíveis (inter)traduções, o que solicita o apoio de disciplinas da antropologia e arqueologia, dos estudos da tradução, da narratologia e análise do discurso, das ciências biológicas e ambientais, da computação e ciências da informação.

A idealização deste número, pensado por Andréia Guerini e Marie-Hélène Torres, e que contou com a colaboração de José Guilherme dos Santos Fernandes, teve o cuidado de publicar as traduções de textos pouco acessíveis, esgotados, alguns inéditos em 
português, acompanhados de textos introdutórios dos tradutores. Trata-se, em geral, de textos de autoria de botânicos, etnógrafos, geógrafos, naturalistas, escritos em línguas estrangeiras por estrangeiros, sobre a Amazônia, em relatos de viagem, diários, discursos ou correspondência, entre outros. Os textos aqui selecionados foram escritos em alemão, espanhol, francês, inglês e italiano, entre o século XVII e o início do século XX.

Os textos introdutórios dos tradutores contextualizam as obras e autores, além de explicitar algumas estratégias de tradução. A preocupação com o leitor levou os tradutores a contornar o ponto de vista dos autores dos textos de partida com notas explicativas. Esses textos dos tradutores discutem questões fundamentais de tradução como comentário de tradução enquanto experiência metalinguística (Nascimento e Cancela); ecotradução (Torres); a especificidade da tradução de textos históricos (Bezerra, Cesco), de textos protofeministas (Simoni), de textos científicos (Harden e Harden; Freitas e Nascimento) e de textos relativos à etnografia e língua-cultura indígenas como os Xipaya e Kuruaya (Branco e Rohr ; Arnegger e Sanjad).

A diversidade de miradas sobre a Amazônia se concretiza em traduções de várias nacionalidades e línguas, notadamente dos países colonizadores, como o espanhol, o francês, o alemão e o inglês, sem mencionar nossa realidade lusófona para a qual as traduções são direcionadas. De todo modo, carecemos, enquanto falantes do português, dessas visões outras para além daquelas herdeiras de Pero Vaz de Caminha, e que podem somar-se a um feito curioso destes escritores que desembarcaram na Hileia desde o século XVI: "recriar nas terras do Novo Mundo (...) aquelas histórias que a literatura grega difundiu" (TOCANTINS, 2000, p. 47).

Isso fez com que muitos relatos corridos e vagos dos nativos logo fossem adaptados aos desejos dos viajantes e, em alguns casos, 
conquistadores. Essa prática colonial, observada em um primeiro momento dos contatos e relatos, vem confirmar aos colonizadores seu direito "legítimo" a uma terra supostamente nula de povos, unicamente existindo ao natural, sem interveniência de qualquer "alma" humana, reforçando o jus possidendi romano, direito de propriedade conferido a quem tem a posse, no caso, os desbravadores europeus das terras ameríndias. Assim, consideramos que os relatos advindos dessa prática podem ser classificados como viagens possessórias, ou seja, havia a necessidade de se justificar a tomada e posse da terra que acreditavam ter achado, ou descoberto, o que foi legitimado pelos seus relatos.

Neste tipo, enquadra-se a tradução que Andrea Cesco e Mara Gonzalez Bezerra apresentam da introdução de José Toribio Medina (1852-1930) acerca da Relación, do frei espanhol Gaspar de Carvajal, cronista da expedição de Francisco de Orellana (15111546), em que se ratifica a participação dos espanhóis na história da Amazônia. E mais, este documento é testemunho do genocídio impetrado naquele momento contra os indígenas, mas que é visto como batalha épica da conquista do território, aos moldes dos argonautas gregos, que também tiveram que enfrentar mortandade frente às intempéries da região, assim como doenças, mosquitos, frustrações, que os levaram a batizar o atual rio Amazonas como rio Marañón, ou rio das Marañas, no sentido de desgraças e aflições, segundo as tradutoras.

Na mesma linha de viagens possessórias, encontra-se a tradução de Joaquim Martins Cancela Júnior e Lilian Cristina Barata Pereira Nascimento, acerca dos excertos de Conversión de Piritu, de Ruiz Blanco. Nessa tradução, Blanco, que era missionário nas regiões de Piritu e Cumaná, na atual Venezuela, trata do período em que esteve na região, de 1672 a 1708, então como frei, com 27 anos, quando aprendeu a língua cumanagota, fundou povoados, catequizou os povos e realizou o serviço religioso de catequese para os demais religiosos, e ainda produziu farta obra sobre as línguas indígenas com as quais teve contato. Se Carvajal trata dos feitos militares e épicos dos espanhóis, na obra Conversión de Piritu existe a 
preocupação de oferecer "metodologia" para a conversão indígena ao cristianismo. Portanto, são obras em que as bases do processo colonizatório são lançadas, pautadas na ética do aventureiro, que "ignora fronteiras" e "vive dos espaços ilimitados, dos projetos vastos, dos horizontes distantes" (HOLANDA, 1995, p. 44).

Mais interessados, de outro modo, em suceder os ditames colonizadores, o que classificamos como relatos de viagens exploratórias vêm a ser o destaque prioritário da natureza amazônica - fauna e flora - em quadro barroco delineado pelo hiperbólico e antitético da paisagem, em que o humano é coadjuvante. Quando muito esta humanidade "amazoníndia" é vista como objeto de estudo em cenário edênico, merecendo o olhar e as palavras acuradas da etnografia, na busca de compreensão dos passos do processo civilizatório, que nos levariam da selvageria à civilidade. É o que notamos na tradução do texto de Journal of a Passage from the Pacific to the Atlantic (1829), de Henry Lister Maw e nas traduções de textos de Emilie Snethlage, naturalista e etnóloga alemã que foi Diretora do Museu Paraense Emílio Goeldi, no período de 1914 a 1921, sendo pioneira nesta instituição como pesquisadora.

Em um dos textos de Emilie Snethlage, traduzido por Cilene Trindade Rohr e Rosanne Castelo Branco, apresenta-se um estudo sobre as etnias Xipaya e Curuaya, no Médio Rio Xingu, em que o enfoque são as relações sociais e os comportamentos migratórios das destas etnias indígenas, que habitavam as margens dos rios Iriri e Curuá, e que, com a chegada do homem branco realizavam frequentes migrações, conforme este estudo de 1910.

O segundo texto é uma tradução de Reinhard Michael Eugen Arnegger Nelson Sanjad (Museu Paraense Emílio Goeldi) a partir de ata da Associação Berlinense de Antropologia, Etnologia e Pré-História, onde constam preciosas informações dos cientistas e naturalistas alemães dedicados aos estudos sobre o Brasil e a Amazônia. Mme Snethlage constituiu considerável coleção de artefatos sobre os Xipaya e Kuruaya, sendo ainda hoje a única coleção no mundo acerca destas etnias, abrigada no Museu de Etnologia de Berlim. 
Ainda na linha do hiperbólico da natureza, esta edição de $\mathrm{Ca}$ dernos de Tradução dispõe sobre o texto dos membros da Missão Bávara, em princípios do século XIX, em que estavam o jovem botânico Carl Friedrich Philipp von Martius e o zoólogo Johann Baptist von Spix, membros da Real Academia de Ciências de Munique. A tradução de Alessandra Ramos de Oliveira Harden e Theo Harden apresenta parte da viagem do Rio de Janeiro à região amazônica de Spix e Martius. Segundo a apresentação dos tradutores, "os dois levaram para a Europa ' 5 espécies de mamíferos, 350 de pássaros, 130 de anfíbios, 116 de peixes, 2700 de insetos, 80 de aracnídeos, 80 de crustáceos e 6.500 espécies de plantas, compondo um herbário de 20.000 exemplares' (Lisboa 91, nota 24) e um casal de crianças indígenas (originalmente eram quatro crianças, mas apenas duas sobreviveram à viagem) do Amazonas". A exemplo de Mme Snethlage, os alemães reuniram grande quantidade de material botânico e enviaram à Europa, o que certamente fortaleceu a visão de ciências naturais, que passou a ser a referência do que seria ciência, estabelecida em fins do século XIX e primeira metade do século XX. Nesse cenário, a Europa torna-se o centro do conhecimento universal e detentora da palavra final sobre os povos e suas evoluções: nascia e se fortalecia o evolucionismo, que tanto legou de estatuto ao etnocentrismo.

Para finalizar os textos das viagens exploratórias, esta edição apresenta a tradução com notas de Luana Ferreira de Freitas e Kelvis Santiago do Nascimento sobre os capítulos XXI e XXIII de $A$ voyage up the river Amazon with a residence in Pará, de autoria de William H. Edwards (1822-1909), realizada em 1846. Reconhecidamente a posteriori um entomologista, a importância dessa obra está na revelação de encontros culturais assimétricos, em deslavada discrepância entre o mundo de colonizadores e de colonizados culturalmente, particularmente a mestiçagem, que se apresenta como um processo degenerativo da espécie humana, numa incompreensão, para não dizer discriminação, acerca das fricções interétnicas.

Por fim, temos as viagens utópicas, referentes ao sentido mais estreito da palavra utopia: lugar ou estado ideal, de felicidade e 
harmonia. Nesses textos, encontramos a descrição-narrativa da poética da Amazônia, onde as autoras imiscuem datações em envolventes cenários e acontecimentos, desde suas impressões sensoriais e memorialistas. Não que inexista a crônica de viagem, mas a escritura se torna arrebatadora, pois a condução em detalhes acerca dos movimentos, da natureza e dos seres, inclusive humanos, nos motiva a entrar em cena, como o "homem na multidão" baudelairiano. E falamos de autoras? Sim, já que são duas escrituras femininas. A despeito de terem realizado viagens acompanhando seus maridos, esses são obscurecidos pela originalidade e expressividade das memórias dessas mulheres.

A primeira obra é de Gemma Ferruggia, italiana que esteve no Brasil em 1898 e 1921, publicando em 1902 o livro Nostra Signora del Mar Dolce. Missioni e Paesaggi di Amazzonia, do qual Karine Simoni traduz para esta edição o capítulo VI, intitulado "Madonna Fantasia”. É importante ressaltar que é uma escritura para além da crônica de viagem ou de tratado botânico-etnográfico, sendo narrativa de experiência de vida e frutífera imaginação poética. Para a tradutora, "as paisagens cobertas por florestas tropicais, campos, igapós, rios e lagoas, e a presença de contingentes humanos de culturas até então nunca vistas, têm provocado estupor e fascínio, que nutriram e nutrem a ambição e o desejo de aventureiros e exploradores em conhecer e apossar-se do lugar", e a presença feminina, mesmo que rara, imprimiu outro olhar, descentrado do foco masculino.

A segunda tradução neste tipo de viagem é a de Alexandrine Langlet-Dufresnoy, a primeira europeia a descer o rio Arinos, no Mato Grosso. Seu relato de viajante originou Quinze ans au Brésil ou Excursions à la Diamantine [Quinze anos no Brasil ou excursões em Diamantino], ocorreu de julho de 1837 (capítulo I) a agosto de 1852 (capítulo IV), sendo que para este edição foram traduzidos os dois capítulos, já referidos. A tradutora Marie-Hélène Torres enquadra sua tradução como ecotradução ou ecotranslation, porque entende que Mme Langlet-Dufresnoy fixa a natureza como tema, personagem e reflexão, vinculada a contextos culturais. 
O êxtase declarado nessas viagens utópicas proporcionou uma qualidade de escritura, acerca da Amazônia, que ainda hoje insiste no tratamento hiperbólico e anímico da região, seja por parte dos literatos, dos jornalistas e até de cientistas sociais. No entanto, como assinala Fernandes

\begin{abstract}
Não que de todo essas qualidades não possam existir na compreensão de mundo deste homem (amazônida), mas daí a dizer que o caboclo vive primordialmente num mundo de devaneios, contemplações e êxtases face à natureza circundante, numa autêntica "ilha da fantasia", é no mínimo negar-lhe a diversidade de pensamento e sua propriedade de ser histórico e que por isso, também, vive o conflito, as antíteses de qualquer relação entre culturas e destas com a natureza (FERNANDES, 2006, p. 75).
\end{abstract}

É inegável que esta edição de Cadernos de Tradução tem a mesma importância, para os pesquisadores e estudiosos da Amazônia, ou amazonistas, que os gregos relevaram ao velo de ouro: a de embarcar em nossa Argos mais vozes e discursos que, mesmo não sendo os dos povos originários apagados pelo genocídio colonial, podem ecoar o testemunho do encontro entre culturas. Num ato de espelhamento, acabamos por saber muito mais sobre nossos colonizadores do que os viajantes suporiam no momento de debruçaremse sobre o papel e lançarem-se à faina gráfica.

Em sua tarefa de registrar as belezas e agruras do "grande-rio das desgraças e aflições”, ou Grão-Pará del Marañón, os viajantes de antanho realizaram a primeira tradução, ou ficção, na medida em que colocaram em sua escala de estrangeiro o que para eles seria a Amazônia. Em segunda mão, os tradutores realizam a segunda ficção, a partir de suas opções e modelos éticos e estéticos. Por 
fim, o leitor traz ao seu universo de representação uma Amazônia de acordo com suas expectativas, ampliadas pelas duas primeiras operações. Mas não é demais lembrar que a existência e re-existência dos amazônidas tem muito a ver com esse passado, forjado em trocas, em lutas e em traduções da Amazônia.

Andréia Guerini ${ }^{1}$

Marie Helene Torres

1-Universidade Federal de Santa Catarina/CNPq

José Guilherme Fernandes²

${ }_{2}^{2}$ Universidade Federal do Pará/Procad/Capes

\section{Referências}

FERNANDES, José Guilherme dos Santos. Escritura e oralidade: versões e ficções da Amazônia. FARES, Josebel (org.). Diversidade cultural: temas $e$ enfoques. Belém: UNAMA, 2006.

GONDIM, Neide. A invenção da Amazônia. São Paulo: Marco Zero, 1994.

HOLANDA, Sergio Buarque de. Raízes do Brasil. São Paulo: Companhia das Letras, 1995.

TOCANTINS, Leandro. O rio comanda a vida. Manaus: Editora Valer, 2000.

Andréia Guerini. E-mail: andreia.guerini@gmail.com. https://orcid.org/00000002-3187-6246.

Marie Helene Catherine Torres. E-mail: marie.helene.torres@gmail.com. https:// orcid.org/0000-0001-9263-0162.

José Guilherme Fernandes. E-mail:mojuim@uol.com.br. https://orcid.org/00000001-9946-4961. 